\title{
A INFLUÊNCIA DA MONITORIA NA INOVAÇÃO PEDAGÓGICA E FORMAÇÃO DOCENTE
}

\author{
Caio Giusti Bianchi ${ }^{1}$ \\ Rosana Pêgas Godoy ${ }^{2}$
}

\section{Resumo}

A monitoria pedagógica tem sido reciclada ao ultrapassarem a dimensão formal e imprimem sentido para o monitor (formação docente), professor (suporte e atualização) e estudante (suporte na aprendizagem). Então, o objetivo da pesquisa é identificar a relevância da monitoria pedagógica para a inovação de técnicas pedagógicas e formação docente na educação de nível superior. Para tanto, foram realizadas sete entrevistas com monitores pedagógicos, analisadas por meio da análise de conteúdo temática. Foram identificados três pilares de influência na monitoria pedagógica: motivação dos monitores em participar do processo; relevância do suporte institucional e do relacionamento interpessoal entre professores, monitores e estudantes.

Palavras-chave Monitoria Pedagógica. Formação Docente. Inovação Pedagógica.

\begin{abstract}
Pedagogical monitoring has been recycled as they exceed the formal dimension and are meaningful for the monitor (teacher training), teacher (support and update) and student (teaching and learning support). The aim of the research is to identify the relevance of pedagogical monitoring for the innovation of pedagogical techniques and teacher education in higher education. To do so, seven interviews with pedagogical monitors were carried out and analyzed through thematic content analysis. Three pillars of pedagogical monitoring influence were identified: monitors' motivation to participate in the process; relevance of institutional support and of interpersonal relationship between teachers, monitors and students.
\end{abstract}

Keywords Pedagogical Monitoring. Teacher Training. Pedagogical Innovation.

\section{INTRODUÇÃO}

A inovação de técnicas pedagógicas sugere mudanças qualitativas nas práticas educativas antes (planejamento), durante (atividades que mobilizem os estudantes) e depois da sala de aula (feedback). Esse posicionamento envolve um pensamento crítico perante as práticas tradicionais, já que há transposição de novos contextos de aprendizagem (FINO,

\footnotetext{
${ }^{1}$ Escola Superior de Propaganda e Marketing (ESPM). Email: rrpegas@ gmail.com

${ }^{2}$ Escola Superior de Propaganda e Marketing (ESPM). Email: rrpegas@ gmail.com
} 
2008). A inovação metodológica na pedagogia, como pautado no Tratado de Bolonha (1999), envolve o compromisso de as instituições educacionais colaborarem para o desenvolvimento de competências interpessoais, utilizando-se de recursos de monitoria com um envolvimento efetivo no processo de ensinar e aprender dos estudantes (LEITE E RAMOS, 2012).

A monitoria pedagógica tem como característica principal auxiliar o professor titular da disciplina no desenvolvimento de atividades realizadas em diferentes espaços de aprendizagem, e não apenas na sala de aula; contribuindo de forma efetiva para o processo de ensino e aprendizagem e, consequentemente, para a ampliação do repertório conceitual dos estudantes (BORSATTO et al., 2006). Nesse ambiente educacional, as atividades de monitoria pedagógica também pressupõem que o professor exerça responsabilidades de orientador dos monitores, compartilhando e recomendando leituras, incentivando a reflexão e compartilhando a prática pedagógica em significados com os futuros professores (FRISON E MORAES, 2011).

Tendo em vista as características da inovação de técnicas pedagógicas e sua necessidade por conta das mudanças em relação às práticas tradicionais de ensino, o papel da monitoria tem sua relevância maximizada. Portanto, o objetivo do artigo reside em identificar a relevância da monitoria pedagógica para a inovação de técnicas pedagógicas e a formação docente na educação de nível superior.

O estudo de caso foi baseado em sete entrevistas com monitores pedagógicos inscritos no Programa Institucional de Monitoria Pedagógica promovido por uma Instituição de Educação Superior localizada na cidade de São Paulo. Após as entrevistas, foi utilizada a técnica de análise de conteúdo temática nas transcrições, a fim de alcançar temas principais no que tange a experiência de monitoria pedagógica.

\section{REVISÃO DA LITERATURA}

\section{As Escolas da Educação}

Os conceitos de hegemonia e contra hegemonia foram formulados em meio à reminiscência marxista, onde processos de transformações sociais adquiriram um papel central, indicando rupturas com o processo da supremacia da classe intelectual. O processo contra hegemônico também foi direcionado à educação em um sentido amplo: promover a classe proletária ou aqueles que estão subordinados à classe dominante (ALVES, 2010).

Segundo Manacorda et al. (2002), após a Segunda Grande Guerra, foi criada uma divisão da pedagogia entre os Estados-nação. De um lado, escolas que atendiam a democracia burguesa, 
inspiradas em pesquisa e desenvolvimento; de outro lado, escolas que atendiam ao proletariado, inspiradas tanto na pedagogia como no conhecimento útil, aplicado pelo e para o trabalho. Assim, emergiu uma visão dualizada da educação: a escola clássica destinada às classes dominantes e a escola profissionalizante destinada aos países com forte presença de classes trabalhadoras e responsáveis por trabalhos instrumentais.

Ao trazer essa dualidade para o contexto atual, é importante refletir sobre o fato de a educação estar sendo desafiada a acompanhar a revolução tecnológica na medida em que tal revolução impõe outro ritmo à produção e difusão do conhecimento, democratizando o acesso a dados e informação e colocando em dúvida o protagonismo das instituições educacionais na produção do conhecimento. É evidente, segundo Lauzon (1999) que a aprendizagem não está separada do mundo da ação, sendo ela também um processo social e um conhecimento construído por meio das relações cotidianas. Segundo o autor, todas essas mudanças estão ligadas à epistemologia da educação, que passa a construir uma ordem lógica do ser reflexivo e prático.

De acordo com Alarcão (2001), é possível afirmar que as transformações no plano das ideias e da cultura apontam para uma educação como meio de promoção do desenvolvimento onde os modos de pensar e agir em sociedade são valorizados. Essa nova maneira de pensar tem implicações na formação do professor, na elaboração do currículo, e na forma pela qual os estudantes são reconhecidos no processo que envolve ensino e aprendizagem.

Nesse contexto, o investimento em programas de monitoria pedagógica amparados na inovação de técnicas pedagógicas a partir de metodologias ativas pode ser materializado em três aspectos: 1) identificação de jovens interessados no exercício da docência; 2) contribuição conceitual e prática para a profissionalização de tais jovens; e 3) melhoria do processo de ensino de aprendizagem em uma instituição a partir do suporte de monitores pedagógicos e apoio institucional para tal.

\section{Inovação de Técnicas Pedagógicas}

A educação está relacionada com o desenvolvimento da própria sociedade, de modo que jovens e adultos são educados para suprir falhas no sistema produtivo, econômico e político. Assim, os processos de escolarização estão relacionados à transformação dos países, incluindo a inserção do estudante na sociedade vigente ou emergente de acordo com a sua origem social (FORTES, 2012). 
Os processos de inovação na educação estão relacionados à criação de ambientes que favoreçam a aprendizagem dos sujeitos envolvidos. Assim sendo, a preocupação de como ocorre a aprendizagem tem mobilizado a agenda de pesquisa de cientistas de diversos campos teóricos há décadas. Nessa trilha, a literatura é classificada a partir de cinco correntes teóricas: 1) behaviorista (Pavlov, Skyner e Watson, por exemplo); 2) humanista (Roger e Maslow, por exemplo); 3) cognitivista (Gagne, Lewin, Ausubel, Bruner e Piaget, por exemplo); 4) cognitivista social (Brandura, por exemplo); e 5) construtivista (Dewey e Vygotsky, por exemplo) (Merriam et al., 2012). A utilização dos princípios subordinados à psicologia cognitiva e a pedagogia construtivista tem contribuído para modernizar a atividade de ensino, alterar o papel tradicional de professores e estudantes no processo educacional e promover mudanças na arquitetura curricular e na aquisição de conhecimento de alta qualidade, além do desenvolvimento de competências valorizadas pela economia do conhecimento (KöNINGS et al., 2007).

Apesar de não ser um teórico da aprendizagem, Illeris (2002) contribui para o avanço das reflexões teóricas ao associar distintas teorias de aprendizagem, propondo as "teorias contemporâneas da aprendizagem”. Para tanto, associa os processos internos (dimensão psicológica da aprendizagem) aos externos (a dimensão social da aprendizagem) envolvidos com a aprendizagem. Detalhando a proposta, o Illeris (2013) desenvolve um "modelo de aprendizagem" tendo como referência a educação formal. Para tal, afirma que a aquisição dos conteúdos também é dividida em duas dimensões: a relacionada ao conteúdo e a relacionada ao incentivo. A relação entre estas dimensões ocorre a partir do momento em que o autor reconhece a influência exercida pelo ambiente no processo interno do indivíduo. Sendo assim, o modelo proposto envolve três dimensões: cognição, emoção e social (Figura 1).

A dimensão "cognição" está relacionada ao processo interno da aprendizagem, particularmente à dimensão psicológica do indivíduo, na medida em que envolve a sua capacidade de imprimir significado ao conteúdo. A dimensão "emoção" está relacionada aos fatores que mobilizam o indivíduo a desenvolver competências, ou seja, o que faz com que o indivíduo canalize energia mental no processo de aprendizagem. A dimensão "social”, por sua vez, está relacionada ao processo externo da aprendizagem, responsável pelos estímulos do processo de aprendizagem como a empatia, cooperação, comunicação e socialização. Tal dimensão social influencia e é influenciada pelas dimensões de cognição e emoção, sendo inspiradas por autores como Marx, Piaget e Freud, respectivamente. 
Figura 1 - Modelo de Aprendizagem de Illeris

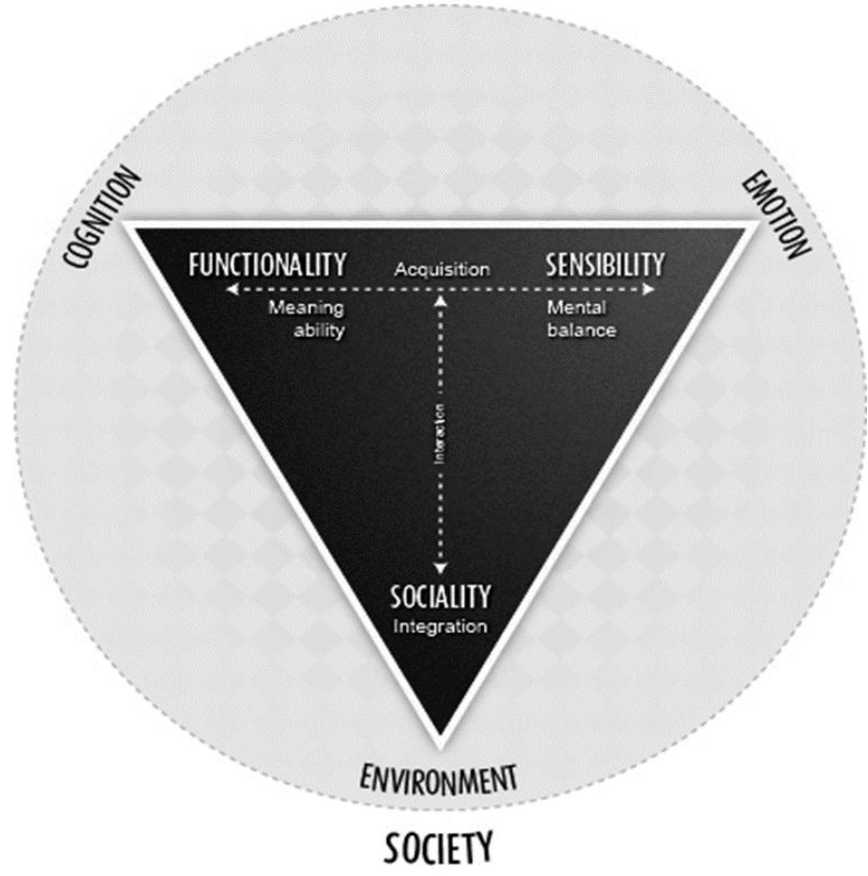

Fonte: Illeris (2013).

Reconhecendo a aprendizagem como um processo permanente de transformação do sujeito, Illeris (2013) reconhece a existência de dois tipos de aprendizagem: a aprendizagem informativa e a transformadora. A aprendizagem informativa colabora para a transformação do indivíduo ao ampliar o seu repertório com novas informações, no entanto, as referidas informações não geram reflexões que possibilitam a transformação do sujeito. A aprendizagem transformadora, por sua vez, mobiliza as três dimensões do processo de aprendizagem e exerce influência na transformação da compreensão do indivíduo em relação à sua realidade, ampliando dessa forma os seus horizontes e suas competências.

De acordo com Fino (2008), para os professores que se acomodaram na rotina imposta pelo modo tradicional de ensinar, a ruptura teórica e prática resultante dos desafios de uma aprendizagem transformadora são de difícil compreensão, já que tendem a encontrar limitações de uma educação regulada pela institucionalização. Subverter tal lógica equivale a promover rupturas de natureza cultural, em que o sentido da universidade, da educação superior, do currículo, e das responsabilidades de estudantes e professores carecem de ser reescritos.

\section{O Papel da Monitoria Pedagógica}

Revista de Administração Educacional, Recife, V. 1 . № 1 . 2017 jan./jun. 2017 p.82-99 
Tradicionalmente, a monitoria pedagógica assume três funções: 1) apoiar os professores titulares no processo que envolve planejamento, ensino e feedback da disciplina; 2) apoiar o processo de aprendizagem dos estudantes; e 3) contribuir para a formação de jovens professores na medida em que envolve ação-reflexão. Segundo Natário e Santos (2010), o trabalho do monitor pedagógico tem por finalidade otimizar a qualidade do ensino e contribuir para a formação integral do estudante.

Assim, o investimento na criação e consolidação de um programa de monitoria pedagógica beneficia a instituição de educação superior, o curso envolvido, o professor titular da disciplina, os estudantes e monitores (LINS et al., 2009). O objetivo do programa de monitoria pedagógica, além maximizar a qualidade do ensino, reside em favorecer a renovação de caráter pedagógico para todos os agentes envolvidos, oferecendo capacitações para o melhor aproveitamento do processo de inovação de técnicas pedagógicas (FRISON E MORAES, 2011).

Quando a aprendizagem é regulada pelo estudante, como advogam os teóricos de metodologias ativas, as vivências decorrentes da aprendizagem tendem a promover a desconstrução e reconstrução do conhecimento. Isso incide sobre o desenvolvimento de competências humanas, proporcionando ao estudante maior controle sobre o seu aprendizado e autonomia. A aceitação consciente dos progressos realizados em sala de aula é também uma importante variável para o desenvolvimento da percepção de sua potência pessoal (LOPES DA SILVA, 2013).

Dentre os objetivos educacionais propostos pelas metodologias ativas, como a assertividade do objeto de estudo, a mobilização das tarefas de acordo com sua dificuldade, a persistência e esforço frente aos desafios da aprendizagem, há a emergência de um plano estratégico e direcionado ao estudante, sendo essencial para a autorregulação e monitoramento do próprio aprendizado (LOPES DA SILVA, 2013). No contexto das metodologias ativas, o aprofundamento dos conteúdos previstos no plano de ensino e aprendizagem proposto pelo professor é parte das responsabilidades dos estudantes. Isso requer mobilização, comprometimento e pró-atividade dos mesmos, com a monitoria pedagógica tendo a responsabilidade de tornar o processo mais interativo e dinâmico (JESUS et al., 2012). 


\section{METODOLOGIA}

A presente pesquisa possui caráter exploratório (DOS SANTOS, 2010) na medida em que discute a monitoria enquanto espaço de formação e auto formação para além dos resultados alcançados por outros estudos. Observa-se que os textos que discutem temas correlatos assumem as características de um ensaio acadêmico (LARROSA, 2003). A pesquisa foi baseada nos procedimentos do método de caso único (YIN, 2010), uma vez que o interesse reside em compreender o significado da experiência de monitoria a partir de estudantes de um programa de pós-graduação em Administração que, no momento do registro das narrativas, vivenciavam a monitoria pedagógica em disciplinas de cursos de pós-graduação lato sensu.

A unidade de estudo é um programa de monitoria pedagógica oferecido por uma instituição de educação superior com cursos de graduação, pós-graduação lato e stricto sensu em sua carta de serviços. O referido programa de monitoria pedagógica é estruturado na medida em que é sujeito a um regulamento, seleciona mestrandos e doutorandos internos à instituição e oferece um programa intenso de capacitação em diferentes técnicas e metodologias ativas para professores e monitores pedagógicos. Os monitores, além de serem capacitados e passarem por um processo de seleção que consiste no envio do currículo lattes, carta de motivação e adequação da área de pesquisa com as disciplinas disponíveis, também são acompanhados ao longo do semestre por um gerente responsável por balizar as experiências, apontar oportunidades de melhoria e novas práticas pedagógicas.

Em relação à coleta de dados, foram realizadas entrevistas com sete monitores pedagógicos que se predispuseram a colaborar com a investigação em curso. As entrevistas foram realizadas de maneira aberta e com foco na reflexão dos monitores em relação à experiência de inovação de técnicas pedagógicas. Com tal abertura e incentivo à reflexão, foi possível captar as principais aflições, benefícios e temas sobre o assunto (RocHA et al., 2004).

O material resultante das entrevistas foi transcrito e organizado de acordo com a técnica de análise de conteúdo temática (BARDIN, 2000). As entrevistas transcritas foram tratadas de modo a se tornarem significativas aos objetivos da pesquisa, com a codificação permitindo atingir uma amostra de dados capaz de satisfazer o objetivo da presente pesquisa, ou seja, os desafios e contribuições que a monitoria pedagógica pode oferecer frente ao processo de inovação de técnicas pedagógicas (BARDIN, 2000).

\section{RESULTADOS}


Após a coleta e análise dos dados, e utilizando como base a técnica de análise de conteúdo temática, foram destacados três temas principais que permearam os dados coletados: 1) motivação dos monitores para participação no programa; 2) influência da capacitação promovida pela instituição; e 3) importância das relações interpessoais na eficácia do processo de inovação de técnicas pedagógicas. Os três temas permitem uma reflexão sobre a experiência dos monitores pedagógicos como facilitadores da inovação de técnicas pedagógicas executada pelos professores titulares das disciplinas.

\section{Motivação}

Dentre as motivações observadas para a participação do programa da monitoria pedagógica, os principais tópicos foram a preparação para a docência e o aprimoramento das competências para os monitores que já lecionam. O interesse também foi presente para aqueles que desconheciam as metodologias ativas e estão sensibilizados para a relevância da inovação de técnicas pedagógicas no processo de ensino e aprendizagem. Os excertos a seguir representam as duas motivações supracitadas:

Meus interesses em participar no programa de monitoria pedagógica eram de aprender mais métodos de como conduzir aulas. Durante o mestrado fui apresentado a vários modos de como conduzir as aulas e obter resultados diferentes com metodologias diferentes, mas sempre do lado do professor. No Programa de Monitoria, não pude ministrar a aula, mas aprendi muito quando pude ouvir o que os alunos esperavam e o que estavam achando das aulas. (Excerto da entrevista do Monitor 2)

Acredito que vivenciar a experiência junto ao professor e estudantes em uma sala de aula é uma oportunidade ímpar, agrega um valioso aprendizado, sobretudo em se tratando de cursos em nível universitário, e da sensibilização para a implantação das metodologias ativas. É um ganho imenso para nós, que estamos no mestrado e doutorado, podermos começar a aprender com a experiência prática, observar, colaborar e se preparar para futura docência. (Excerto da entrevista do Monitor 5)

A capacitação que precede a experiência de monitoria permite que os monitores interessados pela experiência tenham acesso a reflexões teóricas sobre inovação de técnicas pedagógicas e as metodologias ativas a serem implantadas em sala de aula. Isso foi particularmente valorizado pelos monitores principalmente porque, para a maioria, a monitoria representou o primeiro contato com a docência superior e com a inovação de técnicas pedagógicas por meio de metodologias ativas. O excerto a seguir ilustra o reconhecimento da importância da capacitação sobre metodologias ativas, ao mesmo tempo que representa a necessidade de constante ampliação da carga e metodologias a fim de potencializar a capacitação de monitores e professores:

Revista de Administração Educacional, Recife, V. 1 . No 1 . 2017 jan./jun. 2017 p.82-99 
Participei das atividades de capacitação, as quais contribuíram muito para a atividade de monitoria, no entanto, penso que a carga horária dessas capacitações foi pequena. (Excerto da entrevista do Monitor 3)

\section{Suporte Institucional}

A capacitação dos monitores pedagógicos é seguida do acompanhamento da atividade ao longo do semestre pelo gerente do programa. Nessa ocasião, dúvidas e dificuldades são relatadas e, dada a criação de uma comunidade de práticas pedagógicas, os monitores são encorajados a se ajudar. Uma vez que se capacitam para colaborar com os professores titulares, não raro o monitor pedagógico faz sugestões cabíveis aos docentes, considerando a pertinência conceitual e pedagógica. Para sinalizar o nível de confiança e abertura existente entre monitores pedagógicos e professor titular, algumas situações vivenciadas na capacitação foram utilizadas como exemplo, conforme relatado abaixo:

Sim, participei [do planejamento da disciplina] e [as capacitações] colaboraram muito. Pude sugerir algumas atividades à professora através de exemplos vivenciados nestas capacitações. (Excerto da entrevista do Monitor 5)

Outro relato extraído das entrevistas se refere a reuniões regulares promovidas pela coordenação do programa de monitoria pedagógica. Via de regra, elas ajudam os monitores a perceber a importância de sua presença em aula, na mediação que consegue fazer entre estudantes e professor, contribuindo para uma postura mais adequada ao ambiente de aprendizagem que é a sala de aula. Abaixo relato sobre o papel do gerente:

O gerente tem sido um monitor extremamente próximo e atencioso, e creio que com todos estes facilitadores fica mais leve e segura a nossa atuação. (Excerto da entrevista do Monitor 5)

Meus principais apoios foram: leituras dos materiais que estão no site do programa, experiência dos colegas e materiais publicados na comunidade, incluindo aqui, as orientações do gerente. (Excerto da entrevista do Monitor 1)

Além das reuniões presenciais, foi criada uma comunidade de prática nas redes sociais. Ela tem por objetivo ser um espaço virtual de compartilhamento utilizada por todos os monitores. Aqui, com frequência estipulada no início do semestre, os monitores compartilham experiências, reflexões, textos (artigos, livros, relatórios etc.), expectativas, dúvidas e dificuldades vivenciadas. Tais informações possibilitam que haja um acompanhamento e balizamento da experiência dos monitores, com a gerência responsável pela melhor eficácia 
dos monitores pedagógicos em casa. A importância da comunidade pode ser constatada nos relatos a seguir:

de todas estas fontes, eu tenho utilizado muito o material que foi disponibilizado desde as capacitações realizadas, bem como os relatórios, depoimento, exemplos compartilhados pela comunidade da monitoria. (Excerto da entrevista do Monitor 5)

Me apoio muito em leituras, na experiência de outros colegas, no material de discussão publicado e muito no apoio e feedback de nosso gerente. (Excerto da entrevista do Monitor 4)

\section{Relacionamento Interpessoal}

Os monitores consideram que a experiência de monitoria é limitada quando não possuem liberdade para participar das etapas de planejamento da disciplina (elaboração do Plano de Ensino e Aprendizagem) e de feedback oferecidos aos estudantes (com as metodologias ativas, a atividade ganha uma regularidade semanal porque integra o ciclo de aprendizagem). Com a participação, além de entenderem o significado destas atividades, aprendem a desenvolve-las. Esta participação tende a aproximar monitores pedagógicos dos respectivos professores titulares e criar condições que favorecem um relacionamento de confiança entre si, além do ganho no processo de ensino e aprendizagem dos estudantes.

Contudo, a participação no planejamento não ocorre em todas as situações, interferindo na criação de um vínculo pessoal, na aprendizagem do monitor e nas oportunidades de colaboração. Há entrevistados que sinalizam as dificuldades enfrentadas nos primeiros contatos com o professor, a repercussão disso sobre o relacionamento deles e sobre a própria aprendizagem. Seguem alguns relatos que ilustram esta situação:

Duas semanas antes do início da aula, enviei um e-mail à professora informando que eu seria a monitora acadêmica da disciplina, e, na mesma mensagem me coloquei à disposição. Ela respondeu o e-mail informando que posteriormente agendaríamos um horário para poder conversar. Combinamos de nos encontrar meia hora antes do início da aula. (Excerto da entrevista do Monitor 3)

A reunião que tive com a professora foi no mesmo dia que iniciou a aula. Acredito que se tivéssemos conversado antes, eu buscaria as informações antecipadamente para chegar na aula e já estar com tudo estruturado. (Excerto da entrevista do Monitor 5)

Para o monitor pedagógico, assumir um papel ativo em sala de aula gerando contatos e vínculos com os estudantes também é desafiador. A compreensão das metodologias ativas e de suas exigências metodológicas e processuais foi alcançada com a vivência da prática 
compartilhada entre professor, monitor e estudantes. O relato abaixo revela como a introdução de uma nova metodologia em sala de aula é compreendida com o acompanhamento do processo:

Em um primeiro momento [os estudantes] se mostraram ansiosos e preocupados. Mas após a primeira aula com case e a aplicação do primeiro quiz, tudo mudou. Começaram a compreender que seria uma metodologia proveitosa para o maior aprendizado de todos e traria algo que era distante (teoria) para mais perto da realidade do dia-a-dia (prática). Além de mostrar que o certo e errado é uma questão de ponto de vista, sendo exercitados a defender através do uso da teoria e da prática adquiridas. (Excerto da entrevista do Monitor 2)

[Os estudantes] reagiram positivamente, embora tivessem demorado um pouco para entender quais seriam as suas responsabilidades e o que de fato deveriam fazer/desenvolver no decorrer de cada semana. (Excerto da entrevista do Monitor 6)

A mobilização e o engajamento dos estudantes, em grande parte, dependem do quanto conseguem significar os conceitos trabalhados na disciplina. Os monitores reconhecem a ampliação das condições que favorecem a criação de uma rede de significados como uma das grandes contribuições das metodologias ativas. Nesse ambiente de aprendizagem, todos os monitores entrevistados salientam a recorrência com que os estudantes buscam leituras complementares e preparam as leituras em momento anterior às aulas. Isso é particularmente sentido pela adesão aos debates, às discussões propostas, revelando interesse, mobilização, engajamento - atitudes que contribuem para a aprendizagem:

O grau de adesão à proposta pedagógica escolhida foi alto e muito bom. Os indicadores que podem ser utilizados para sinalizar a mobilização dos estudantes é sua grande participação construtiva nas discussões, a melhora nas notas dos quiz, e a conversa no início de todas as aulas, onde foi recorrente escutar dos estudantes que eles estavam gostando dos casos apresentados ao longo da matéria. (Excerto da entrevista do Monitor 2)

\section{DISCUSSÃO}

Com a análise do conteúdo extraído das entrevistas, é possível destacar que o critério de sucesso não se limita no delineamento de passos a serem seguidos por monitores pedagógicos, mas no sentimento de transformação que a inovação de técnicas pedagógicas permite, considerando que é inevitável uma reflexão quanto à prática didática tradicional e as metodologias ativas.

Revista de Administração Educacional, Recife, V. 1 . N 1 . 2017 jan./jun. 2017 p.82-99 
A escolha em participar da monitora pedagógica e suas contribuições está direcionada e relacionada ao interesse em trabalhar com a docência e sua ambição em melhorar o ensino aprendizagem do estudante em sala de aula (NASCIMENTO et al., 2010). Desta forma, foi observado no decorrer das entrevistas uma mobilização dos monitores em compreender seu papel central em sala de aula frente à inovação de técnicas pedagógicas. Conforme citado por Alarcão (2001), e materializado nas entrevistas, o novo modo de pensar e trabalhar a construção do conhecimento em sala de aula tem implicações que permeiam a condução da aula e o modo de construção do conhecimento pelos estudantes.

A compreensão do conhecimento do estudante por meio da resolução de conflitos, diferenças e concordâncias (KOLB E KOLB, 2005) permitiu a maximização do ensinoaprendizagem e engajamento em sala de aula, conforme pôde ser observado nas entrevistas, com a maioria dos estudantes realizando leituras prévias e discussão em sala de aula. É possível ressaltar que o processo de aprendizagem do estudante foi concretizado ao longo da disciplina e que, segundo Illeris (2013), esse processo é composto por dois momentos importantes: a reflexão crítica do estudante; e sua participação livre na aprendizagem autodirigida, alcançando a aprendizagem significativa e reformulação de seus modelos de referência.

Outro destaque é a inspiração dos estudantes em ampliar leituras por meio de pesquisas realizadas com o suporte da tecnologia (HOWARD E GARLAND, 2014). A aprendizagem autodirigida é essencial para levar o estudante a pensar socialmente, onde a conexão com objetos digitais foi imprescindível.

O desempenho do monitor pedagógico em sala de aula foi essencial, já que contribuiu para reduzir a centralização do papel do professor no processo de aprendizagem, contribuindo com o mesmo em todo o processo de planejamento, desenvolvimento e finalização das disciplinas e com as discussões em grupo, impulsionando a busca pelo conhecimento. O papel do monitor em sala de aula não só otimizou a qualidade do ensino, mas também fortaleceu o argumento teórico de que o amadurecimento do estudante ocorre perante seus conhecimento e o mundo que o cerca (NASCIMENTO et al., 2010; NATÁRIO E SANTOS, 2010).

Considerando os aspectos analisados no artigo em relação à literatura explorada, o papel e relevância do monitor pedagógico no processo de inovação de técnicas pedagógicas pode ser sintetizado na Figura 2.

Revista de Administração Educacional, Recife, V. 1 . N 1 . 2017 jan./jun. 2017 p.82-99 
Figura 2: Papel do Monitor Pedagógico como facilitador em sala de Aula.

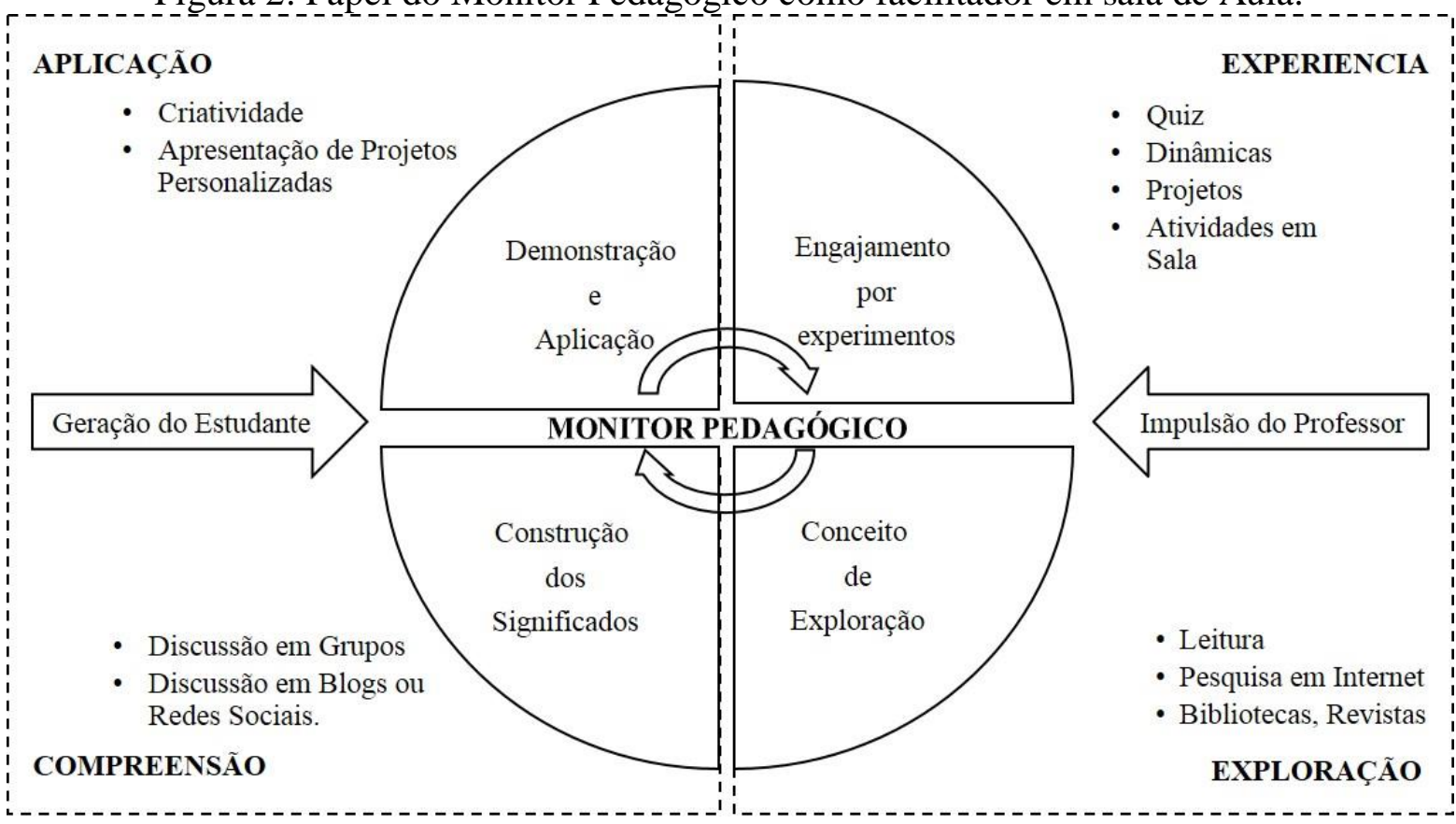

Fonte: Adaptado pelos autores a partir dos dados coletados e Gerstein (2012).

\section{CONCLUSÃO}

Considerando o objetivo da pesquisa de identificar a relevância da monitoria pedagógica para a inovação de técnicas pedagógicas e a formação docente na educação de nível superior, é possível ressaltar alguns pontos. O primeiro ponto é o destaque do papel dos monitores pedagógicos como facilitadores e mediadores da inovação de técnicas pedagógicas. 
Considerando que a inserção de metodologias ativas pelos professores titulares enfrenta, em certa medida, barreiras de mudança paradigmática, os monitores possibilitam a transposição de tais por meio do apoio contínuo, motivação pessoal, bagagem conceitual e treinamentos; além de um aspecto fundamental para a educação: o desejo de construir o conhecimento com os estudantes da melhor maneira possível.

O segundo ponto é o interesse dos monitores pedagógicos pelo programa de monitoria, até mesmo entre os que já exercem a docência no ensino superior. Pare estes, a experiência representa uma possibilidade de aprimoramento da prática docente, particularmente em virtude da vivência com desafios da inovação de técnicas pedagógicas. Para os monitores que estão iniciando a docência, a experiência ganha ares de descoberta, aprendizado e reflexão, ou seja, de formação pedagógica.

Permeando ambos os pontos, é primordial o processo de capacitação e orientação dos monitores pedagógicos e professores realizado por meio do suporte institucional e materializado nos contatos prévios com o professor titular, capacitações em metodologias ativas, treinamentos de comportamento e relacionamento interpessoal realizados pelo gerente do programa e o apoio da comunidade de práticas ao longo da experiência.

Então, o exercício da monitoria pedagógica se mostrou relevante para o desenvolvimento da prática docente dos monitores, seja para a abertura de capacitações docentes ou para o aperfeiçoamento de tais práticas. A relevância do papel dos monitores em sala de aula e o desenvolvimento profissional são ilustrados por três excertos:

Vejo minha atuação como facilitadora, apoiadora no processo de ensino aprendizagem, compartilhando, trocando sugestões para pesquisa e para a busca de resultados. (Excerto da entrevista do Monitor 5)

Foi uma experiência muito gratificante e comprovamos que é possível, prazeroso, estimulante e gratificante observar e ajudar a estimular situações que favorecem a construção de um conhecimento mais sólido e aplicável pelos alunos. (Excerto da entrevista do Monitor 1)

Foi muito importante e significativo para mim fazer parte desta monitoria, conhecendo a metodologia e observando o desenvolvimento dela pelos estudantes passo a passo. Vê-los executando as atividades com tanta dedicação, tanto empenho e tão engajados e colaborando uns com os outros gera uma satisfação muito grande. Estou muito feliz. (Excerto da entrevista do Monitor 6)

Mesmo com a dedicação intensa, as exigências conceituais e metodológicas e os desafios intrínsecos às metodologias ativas, destaca-se a importância da experiência para a formação dos monitores e para a eficácia da inovação de técnicas pedagógicas. Além disso, 
reforçam-se os méritos das metodologias ativas considerando a aprendizagem significativa dos estudantes, sobretudo o quanto tais metodologias os mobilizam para as atividades propostas em sala de aula.

A inovação de técnicas pedagógicas é um processo natural do desenvolvimento da educação, sendo realizada de acordo com as mudanças observadas na sociedade. A inserção das metodologias ativas na educação superior, aliada ao suporte institucional e um programa de monitoria pedagógica, se mostra relevante aos passos que o modelo tradicional de ensino entra em descompasso com as características das gerações atuais.

Tendo isso em mente, a pesquisa possui relevância conceitual no que tange um exemplo de aplicação prática da inovação de técnicas pedagógicas e monitoria, ilustrando como tais conceitos podem ser articulados na realidade. Por outro lado, possui relevância gerencial no que tange o aspecto inspiracional para que outras instituições de ensino superior sejam encorajadas para inovarem pedagogicamente ao identificarem os aspectos mais relevantes e suas consequências positivas.

As principais limitações da pesquisa se referem ao tempo. Considerando que o processo de inovação de técnicas pedagógicas possui um caráter de mudança na cultura organizacional e que tal processo é recente na instituição de ensino em questão, há limitação nas análises e impactos percebidos. Com a expansão do programa de monitoria e a ampliação da abrangência das metodologias ativas nos estudantes, será possível analisar a evolução histórica do processo e, consequentemente, o impacto mais abrangente da inovação de técnicas pedagógicas.

A possibilidade de pesquisas futuras, então, está ampliação da presente pesquisa em outras instituições para identificar padrões de influência, na replicação da pesquisa com foco no histórico de desenvolvimento do processo, ou a comparação do impacto da inovação de técnicas pedagógicas no processo de ensino e aprendizagem frente a metodologias tradicionais de ensino.

\section{REFERÊNCIAS}

ALARCÃO, I. Escola reflexiva e nova racionalidade. Porto Alegre: Artmed, p. 21-30, 2001.

ALVES, A. R. C. O conceito de hegemonia: de Gramsci a Laclau e Mouffe. Lua nova, v. 80, p. 71-96, 2010.

BARDIN, L. Análise de conteúdo. Lisboa: Edições, v. 70, 2000.

Revista de Administração Educacional, Recife, V. 1 . N 1 . 2017 jan./jun. 2017 p.82-99 
BORSATTO, A. Z. et al. Processo de implantação e consolidação da monitoria acadêmica na UERJ e na faculdade de enfermagem (1985-2000). Escola Anna Nery Revista de Enfermagem, v. 10, n. 2, p. 187-194, 2006. ISSN 1414-8145. Disponível em: < http://www.scielo.br/scielo.php?script=sci_arttext\&pid=S1414-

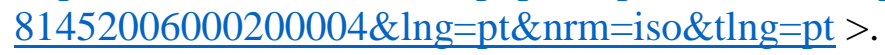

DOS SANTOS, C. J. G. Tipos de Pesquisa 2010.

FINO, C. N. Inovação pedagógica: significado e campo (de investigação). III Colóquio do Centro de Investigação em Educação, 2008.

FORTES, M. C. Teorias da Educação: Qual teoria da educação fundamenta meu cotidiano docente? Educação Por Escrito, v. 3, n. 2, 2012. ISSN 2179-8435.

FRISON, L. M. B.; MORAES, M. A. C. D. As práticas de monitoria como possibilitadoras dos processos de autorregulação das aprendizagens discentes. Poíesis Pedagógica, v. 8, n. 2, p. 144-158, 2011. ISSN 2178-4442.

GERSTEIN, J. The flipped classroom model: A full picture. User Generated Education, 2012.

HOWARD, M. O.; GARLAND, E. L. Social Work Research: 2044. Journal of the Society for Social Work and Research, v. 0, n. 0, p. 000, 2014. ISSN 23342315. Disponível em: < http://www.jstor.org/stable/10.1086/681099 >.

ILLERIS, K. The three dimensions of learning: contemporary theory in the tension field between the cognitive, emotional and social. Roskilde University Press, Frederiksberg, 2002.

Teorias contemporâneas da aprendizagem. Porto Alegre: Penso, 2013.

JESUS, D. M. O. D. et al. Programas de monitorias: um estudo de caso em uma IFES. Revista Pensamento Contemporâneo em Administração, v. 6, n. 4, p. 61-86, 2012. ISSN 1982-2596.

KOLB, A. Y.; KOLB, D. A. Learning Styles and Learning Spaces: Enhancing Experiential Learning in Higher Education. Academy of Management Learning \& Education, v. 4, n. 2, p. 193-212, 2005. ISSN 1537260X. Disponível em: < http://www.jstor.org/stable/40214287 $>$.

KÖNINGS, K. D.; BRAND-GRUWEL, S.; VAN MERRIËNBOER, J. J. G. Teachers' perspectives on innovations: Implications for educational design. Teaching and Teacher Education, v. 23, n. 6, p. 985-997, 8// 2007. ISSN 0742-051X. Disponível em: < http://www.sciencedirect.com/science/article/pii/S0742051X0600103X >.

LARROSA, J. O Ensaio e a Escrita Acadêmica. Educação \& Realidade, v. 28, n. 2, 2003. ISSN 2175-6236.

LEITE, C.; RAMOS, K. Formação para a docência universitária: uma reflexão sobre o desafio de humanizar a cultura científica. Revista Portuguesa de Educação, v. 25, n. 1, p. 07-27, 2012. ISSN 0871-9187. 
LINS, L. F. et al. A importância da monitoria na formação acadêmica do monitor. JORNADA DE ENSINO, PESQUISA E EXTENSÃO, IX, 2009.

LOPES DA SILVA, A. A auto-regulação da aprendizagem: estudos teóricos e empíricos. InterMeio:: Revista do Programa de Pós-Graduação em Educação-UFMS, v. 10, n. 19, 2013. ISSN 1413-0963.

MANACORDA, M. A.; NOSELLA, P.; DOS ANJOS OLIVEIRA, R. História da educação: da antiguidade aos nossos dias. Cortez, 2002. ISBN 8524901632.

MERRIAM, S. B.; CAFFARELLA, R. S.; BAUMGARTNER, L. M. Learning in adulthood: A comprehensive guide. John Wiley \& Sons, 2012. ISBN 0470229225.

NASCIMENTO, C. R. D.; SILVA, M. L. P. D.; SOUZA, P. X. D. Possíveis contribuições das ctividades de monitoria na formação dos estudante-monitores no curso de pedagogia da universidade federal de pernambuco-UFPE. 2010.

NATÁRIO, E. G.; SANTOS, A. A. A. D. Programa de monitores para o ensino superior; Monitor program for university education. Estud. psicol.(Campinas), v. 27, n. 3, p. 355-364, 2010. ISSN 0103-166X. Disponível em:

http://www.scielo.br/scielo.php?script=sci_arttext\&pid=S0103-

$\underline{166 X 2010000300007 \& \operatorname{lng}=p t \& n r m=i s o \& t \operatorname{lng}=p t}>$.

ROCHA, D.; DAHER, M. D. C.; DE ALBUQUERQUE SANT'ANNA, V. L. A entrevista em situação de pesquisa acadêmica: reflexões numa perspectiva discursiva. Polifonia, v. 8, n. 08, 2004.

YIN, R. K. Estudo de Caso: Planejamento e Métodos. Bookman editora, 2010. ISBN 8582602324. 